\title{
A interpretação nietzschiana de Pierre Hadot*
}

\author{
Stefano Busellato**,***
}

Resumo: Com a própria concepção de "filosofia como modo de viver", Pierre Hadot inaugurou uma das mudanças de paradigmas exegéticos mais significativas do período recente. Elaborada a partir de autores antigos, as características e as razões interpretativas desse novo paradigma tornam a proposta de Hadot capaz de abarcar outras épocas e autores diversos. Dentre eles, um papel de destaque é confiado a Friedrich Nietzsche, sobre o qual Hadot detém-se com regularidade e insistência em muitas de suas obras. $\mathrm{O}$ presente artigo oferece uma reconstrução do percurso teórico-filosófico que levou o estudioso francês a elaborar a própria concepção interpretativa e pretende mostrar a leitura que, no interior dele, fazse das especificidades filosóficas nietzschianas. Sua concepção se mostra como uma abordagem diferenciada das páginas de Nietzsche e apresenta elementos de grande originalidade com uma visão que convida a ser refletida e aprofundada.

Palavras-chave: filosofia como modo de viver, história da filosofia, linguagem.

* Traduzido do italiano para o português por Anna Maria Lorenzoni.

** Universidade Estadual do Oeste do Paraná (Unioeste), Cascavel, Paraná, Brasil.

*** Universidade Federal da Integração Latino-Americana, Unila, Foz do Iguaçu, Paraná, Brasil.

ORCID https://orcid.org/0000-0002-8737-6267

Correio eletrônico: stefano.busellato@gmail.com 
Busellato, S.

1. A noção de "philosophie comme manière de vivre", de Hadot, não se esgota na proposta de uma nova categoria historiográfica concernente unicamente à filosofia antiga. Ela pretende ser uma reconsideração global, capaz de alterar o olhar com o qual lemos, interpretamos e pensamos filosofias e filósofos. ${ }^{1}$

Se, por um lado, Hadot está convencido de que um preconceito moderno específico nos impede de entender corretamente as palavras dos antigos - o preconceito de considerar como homogêneas as diversas atividades filosóficas, equiparando-as indistintamente à finalidade exclusivamente teorético-sistemática -, por outro lado, ele insiste sobre o fato de que o timbre peculiar daquelas vozes antigas reverbera-se para além da antiguidade, conseguindo, muitas vezes, superar os muros que as haviam tornado estranhas a nós ou seja, a Idade Média, o nascimento das grandes instituições de ensino, o absolutismo do cristianismo, a revolução gutemberguiana. Hadot está convencido de que esse timbre perdido possa voltar a ser ouvido (como exceção esporádica) também em autores disseminados na história da filosofia subsequente, do renascimento até a nossa contemporaneidade.

Os exemplos fornecidos por ele de autores pós-helenistas que, em suas meditações, abarcam uma essência que dá continuidade a algo de distante, variam de texto para texto. Mas alguns deles se repetem com regularidade: Espinosa, Goethe, Schaftesbury, e, entre os contemporâneos, Nietzsche, Bergson e Wittgenstein. ${ }^{2}$ No interior de um grupo tão heterogêneo, Nietzsche parece ter uma importância peculiar para Hadot. Antes de mais nada, em suas obras, Nietzsche está presente de maneira discreta, porém contínua. Não há texto de Hadot (excluídos os trabalhos estritamente especializados) no qual

1 "O retorno ao passado da filosofia, como Hadot o efetua, conduz, assim, a modificar, retroativamente, o nosso relacionamento contemporâneo com a filosofia” (Jean-François Balaude区, 2008, p. 46).

2 Entre os autores trazido esporadicamente como exemplo de uma filosofia como modo de vida, encontramos o Descartes das Meditações, Pascal, o Rousseau dos Passeios, Kant, Thoreau e Emerson e a corrente fenomenológica, Husserl, Heidegger, Sartre e, particularmente, Merleau-Ponty.

254 | Cad. Nietzsche, Guarulhos/Porto Seguro, v.42, n.1, p. 253-274, janeiro/abril, 2021. 
Nietzsche não seja citado e não apareça nos pontos argumentativos mais importantes. Em segundo lugar, embora modestamente afirmando sentir-se "muito distante de ter compreendido o conteúdo de seu pensamento", Hadot revela também como Nietzsche é um dos poucos autores não pertencentes ao próprio âmbito de estudos que ele "leu e releu". ${ }^{3}$

Conhecido, inicialmente, por meio de Bertram e seu Nietzsche. Versuch einer mythologie [Ensaio de mitologia] (do qual Hadot escreverá o prefácio para a reedição francesa de 1990), ${ }^{4}$ ele demonstra um conhecimento de Nietzsche que em nada se assemelha ao amadorismo. Além de frequentemente se apoiar em outros intérpretes clássicos, entre os quais Adler, Garnier e Fink, Hadot cita diretamente a quase totalidade das obras nietzschianas, utiliza o material póstumo dos fragmentos e das variações, encara um caso de Quelleforschung, ${ }^{5}$ e dedica a Nietzsche um capítulo e dois densos parágrafos, em três de seus textos: o primeiro, sobre a concepção nietzschiana de natureza;

3 Hadot, 2008, p. 71.

4 Ernst Bertram, Nietzsche, Essai de Mytologie, traduit de l'allemand par Robert Pitrou, Préface de Pierre Hadot, Édition du Félin, Paris 1990. É interessante, para melhor compreender o significado de Nietzsche para Hadot, ler o que este escreve a respeito do primeiro contato intermediado pelo texto de Bertram: "Descobri-o inicialmente através de um livro de Bertram, Nietzsche: ensaio de mitologia, que me encantou sobretudo pela sua forma: o livro tem a originalidade de reunir todo tipo de particulares significativos da obra [...] Acredito que seja um método fecundo, na medida em que liga a obra de um autor às várias interpretações que realizou, às visões que teve. Independentemente dessa forma insólita, o livro me revelou um Nietzsche como pessoa na sua extraordinária riqueza da sua vida interior. Esse livro de Bertram, que Thomas Mann admirava, foi contestado pelos especialistas nietzschianos por negligenciar demais a sua doutrina. Mas eu, pessoalmente, acho que o homem Nietzsche, com todas as suas contradições, tenha sido bem destacado nesse livro" (Hadot, 2008, p. 70 - grifo nosso).

5 Trata-se de uma referência a Baubo, que Nietzsche faz no §4 do prefácio de FW/GC. Hadot contesta que Nietzsche tenha em mente a figura feminina mais óbvia, ligada aos mistérios eleusianos rastreáveis em Clemente de Alexandria, Protréptico II,20, 3 e em Eusébio de Cesareia, Preparação evangélica II,3, 34 (como indicam as notas de OFN, V/2, pp. 534-535), e vai adiante com a proposta de que Nietzsche esteja se referindo, em vez disso, ao "terrível demônio noturno, assimilado por Gorgone, que talvez conhecia por que havia falado o seu amigo Erwin Rohde no livro Psiche" (Hadot, 2006b, p. 291-292).

Cad. Nietzsche, Guarulhos/Porto Seguro, v.42, n.1, p. 253-274, janeiro/abril, 2021. | 255 
Busellato, S.

o segundo, sobre a comparação entre Nietzsche e o estoicismo; e, o terceiro, sobre um paralelo entre Nietzsche e Goethe. ${ }^{6}$

Para Hadot, Nietzsche é talvez aquele que, mais do que qualquer outro, herda e renova uma forma de saber antigo e esquecido, como o da "filosofia como forma de vida". Mas ele chega a essa convicção por meio de um caminho interpretativo tão insólito quanto fascinante. Refazê-lo mostra-se como algo útil não apenas para compreender como Hadot lê em Nietzsche uma modalidade diferente de reflexão no interior da história da filosofia, mas também para oferecer uma percepção interpretativa original a respeito de Nietzsche, que pode se abrir com Hadot e pode conduzir para além de Hadot.

2. Para traçar esse caminho, entretanto, Hadot não partiu da antiguidade, mas da contemporaneidade; foi em direção à antiguidade e, após ter se detido nela, fez um retorno à contemporaneidade e a Nietzsche. Mas não foi Nietzsche o filósofo a dar início a esse percurso. Hadot elaborou a própria teoria a partir de Wittgenstein. A concepção de "filosofia como forma de vida" se originou, portanto, no seio de reflexões linguísticas ou, mais precisamente, a partir do tema do silêncio, da mística da linguagem, como Wittgenstein apresenta na parte final do Tractatus logico-philosophicus, que se encerra com a magnífica sexta proposição: "Wovon mann nicht sprechen kann, darüber müß mann schweigen". Foi exatamente essa passagem que chamou a atenção de um jovem estudioso de filosofia antiga.

Em 1959, Hadot trabalhava sobre a questão da mística filosófica, particularmente em Plotino, e casualmente encontrou uma citação que o levou a descobrir que, sobre mística, sobre silêncio e sobre o inexprimível, falava também um positivista lógico, à época

6 Respectivamente, em: Hadot, 2006b, cap. XI "La Natura-Sfinge”, p. 281-296; Hadot, 1992, cap.

"Amor Fati", p. 160-16; Hadot, 2009a, cap.4, "Goethe e Nietzsche”, p. 155-162.

256 | Cad. Nietzsche, Guarulhos/Porto Seguro, v.42, n.1, p. 253-274, janeiro/abril, 2021. 
praticamente desconhecido. ${ }^{7}$ Assim, ele iniciou um estudo sobre a filosofia da linguagem de Wittgenstein ${ }^{8}$ com a intenção de dar uma explicação àquele "enigma fascinante", ${ }^{9}$ aquela contradição em termos, que é o positivismo místico. ${ }^{10}$ Dedicou-se, então, a esclarecer a passagem do lógico ao místico. ${ }^{11}$

O objetivo que Wittgenstein se impôs, com o Tractatus, era uma terapia mística definitiva em comparação com o discurso filosófico, o qual formula problemas que, na verdade, nascem de uma incompreensão da lógica da nossa linguagem. "A maioria das proposições e questões escritas sobre temas filosóficos não são falsas, mas sem sentido". ${ }^{12}$ Para separar o sem sentido (Unsinnigkeit) do com sentido, Wittgenstein apoiou-se no paralelismo lógico-filosófico - herdado de Russell, e, por sua vez, proveniente de Frege -, segundo o qual é necessário voltar a colocar os pés no terreno firme do isomorfismo que conecte, a uma mesma estrutura, os fatos do mundo e a lógica do pensamento, e, portanto, da expressão deste. Apenas as proposições que representam, no mundo físico, um estado de coisas possíveis (Sachveralt) podem reivindicar, logicamente, um conteúdo de sentido.

\footnotetext{
7 Hadot, 2008, p. 178. Basta pensar que ainda faltava uma tradução francesa do Tractatus. A primeira aparece em 1961, pela Gallimard, assinada, curiosamente, por um grande conhecedor de Nietzsche, Pierre Klossowski. Hadot tentou trabalhar, por um certo tempo, na tradução do texto, mas não chegou a concluí-la.

8 São resultado desse aprofundamento os quatro artigos que Hadot publicou sobre o tema: "Réflexions sur les limites du langage, à propos su Tractatus Logico-philosophicus de Wittgenstein", in Revue de Métaphysique et de Morale, LXIII (1959), p. 469-484; "Wittgenstein philosophie du langage I", in Critique, CXLIV (1959), p. 866-881; "Wittgenstein philosophie du langage II", in Critique, CL (1959), p. 972-83; "Jeux de langage et philosophie", in Revue de Métaphysique et de Morale, LXVII (1962), p. 330-43; textos posteriormente reunidos in Hadot, Wittgenstein et les limites du langage, J.Vrin, Paris 2004; trad. brasileira de Flavio Fontenelle Loque e Loraine Oliveira, Wittgenstein e os limites da linguagem. São Paulo: É Realizações, 2014.
}

9 Hadot, 2007, p. 8.

10 Hadot, 2008, p. 243.

11 Hadot, 2008, p. 179.

12 L. Wittgenstein, Tractatus Logico-Philosophicus, 4.003.

Cad. Nietzsche, Guarulhos/Porto Seguro, v.42, n.1, p. 253-274, janeiro/abril, 2021. | 257 
Busellato, S.

Esse é o postulado do Tractatus que Hadot chama "empíricopositivista". Mas tal postulado, para Hadot, começa a mostrar fissuras estruturais no decorrer do Tractatus, precisamente quando Wittgenstein percebe que em toda forma lógica se esconde uma essência tautológica. As constantes lógicas permitem efetivamente a representação linguística, mas não são, por sua vez, representantes (4.0312). Elas não detêm um conteúdo externo a si mesmas, exprimem apenas si próprias $(6.113 ; 6.1 ; 6.124 ; 6.22)$. Partindo do desejo veemente de distinguir o uso representativo do uso sem sentido da linguagem, Wittgenstein descobre, assim, também a natureza tautológica da linguagem lógica. ${ }^{13}$ Daqui resulta, para Hadot, algo de decisivo: a partir dessa descoberta, abre-se um quarto uso possível da linguagem: aquele indicativa, do mostrar [Zeigen] contraposto ao dizer [Sprachen]. ${ }^{14}$ A tautologia não revela apenas que a lógica é autorreferente, mas também que ela mostra a estrutura que possui em comum com o mundo, sem, por sua vez, podê-la dizer. A linguagem encontra, assim, o seu limite. ${ }^{15}$ Mas, dado que o limite é definido como tal apenas se houver algo além dele, este algo é, então, o inexprimível [inexprimable], como o denomina Hadot, o indizível (Unsagbares), como o denomina Ingeborg Bachmann, ${ }^{16}$ o inefável [Unaussprechliches], como o denomina Wittgenstein.

Abre-se, assim, um reino daquilo que está além dos limites linguísticos da expressão possível, o reino do silêncio, daquele calar

13 6.1: "As proposições da lógica são tautologias", 6.2: "As proposições da lógica não dizem, portanto, nada. São analíticas", 4.461; 4.463; 5.525. Cfr. Hadot, 2007, p. 54-65

14 Cf. as proposições 4.12, 4.121, 4.1212 .

15 " $O$ fato de que eu posso falar sobre a minha linguagem me leva a descobrir que sou, eu mesmo, um limite dessa linguagem [...] Gradualmente nos aproximamos ao fim do tratado, o tom de Wittgenstein se anima com uma espécie de tremor imperceptível. Ele, de fato, se aproxima da esfera do místico (ele usa esse termo) e uma espécie de intuição inexprimível se impõe. O que percebe não é mais a ideia abstrata, é o sentimento dos limites da linguagem" (Hadot, 2007, p. 43-44).

16 Ingeborg Bachmann, Sagbares und Unsagbare. Die Philosophie Ludwig Wittgensteins [1953], in , Werke, IV, hrsg. Christine Koschel, Inge von Weidenbaum, Clemens Münster. München: Piper Verlag, 1978; trad. it. di Barbara Agnese. In . Il dicibile e l'indicibile. Milano: Adelphi, 1998, pp. 45-79.

258 | Cad. Nietzsche, Guarulhos/Porto Seguro, v.42, n.1, p. 253-274, janeiro/abril, 2021. 
[schweigen] que é a última palavra com a qual se encerra o Tractatus. "O que se exprime na linguagem não podemos expressar por meio dela", ${ }^{17}$ a linguagem não pode dizer nada além de si mesma, "o que pode ser mostrado não pode ser dito". ${ }^{18}$ Mas, para Hadot, isso significa também que tal excedente relacionado ao dizível, que se encontra fora da linguagem e que não pode ser exprimido precisamente porque é privado de linguagem, a linguagem pode apontá-lo, indicar na sua direção, mostrá-lo. Como o oráculo de Delfos do fragmento

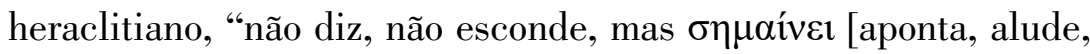
indica, mostra]", ${ }^{19}$ o sem sentido [Unsinnigkeit] que Wittgenstein queria banir da filosofia, retorna, assim, com a voz do silêncio, por meio do gesto de mostrar algo que a linguagem não pode dizer. $\mathrm{Ou}$ quando diz que quem realmente compreendeu as proposições do Tractatus, "por fim as reconhecerá como sem sentido, quando graças a elas - por elas - tiver escalado para além delas. (É preciso por assim dizer jogar fora a escada depois de ter subido por ela) [...] ele deve vencer essas proposições para ver o mundo corretamente". ${ }^{20}$ Para Hadot, isso tudo quer dizer: "Existe todo um domínio no qual, por meio de sua própria falta de sentido, a linguagem mostra aquilo que não pode exprimir. Não é importante, então, aquilo que ela diz, mas aquilo ao qual ela nos permite nos dirigir". ${ }^{21}$

Hadot vê no silêncio final do Tractatus a razão do abandono da vida acadêmica por Wittgenstein; a sua tentativa de uma nova forma de existência, um cotidiano diferente; e explica a tomada de notas, nesse período de transição, de que, se a filosofia ainda quer fazer uso da linguagem, deveria mirar o poder evocativo, que nela se abriu,

17 Cfr. a proposição 4.121 e os comentários de Hadot, 2007, p. 35-36 e p. 70: "Nunca ninguém havia dado voz, de maneira tão clara e profunda, ao que é justo chamar o mistério da linguagem, e que é idêntico ao mistério do mundo".

18 4.1212. Cfr. Hadot, 2007, p. 35.

19 Heráclito, Fr.22 B 93 DK.

20 6.54. Hadot, 2007, p. 46.

21 Hadot, 2007, p. 41.

Cad. Nietzsche, Guarulhos/Porto Seguro, v.42, n.1, p. 253-274, janeiro/abril, 2021. | 259 
Busellato, S.

da impossibilidade de representar, isto é, a "forma fundamental" do discurso filosófico deveria ser aquela que conduzisse ao máximo a função evocativa e indicativa da palavra: a linguagem poética ${ }^{22}$ (e aqui começamos a poder olhar para Nietzsche).

3. Mas é com o segundo Wittgenstein que Hadot completa o quadro que lhe permite a elaboração da ideia da "filosofia como modo de viver". Aquela característica transversal da linguagem, de tender a algo que não é exprimível mediante o dizer, o remeter, com a palavra, a algo que a palavra não é, para Hadot, não representa apenas o maior resultado do Tractatus, mas é também o trait d'union que o liga às Investigações filosóficas. A grande mudança entre os dois períodos se encontra, antes de mais nada, no fato de que o fundamento não se encontra mais naquele paralelismo lógico-físico que se mostrara insuficiente e que agora é repudiado abertamente (PU §23); em segundo lugar, a proposição dotada de sentido não é mais buscada em uma linguagem sígnica que purgue a expressão do ilógico. $\mathrm{O}$ sentido (Sinn) de uma proposição se restabelece no terreno pragmático do uso cotidiano $^{23}$ e passa a coincidir com o esforço estabelecido entre os agentes linguísticos e com o que eles tornam a expressão na prática discursiva. "O significado de uma palavra é seu uso na linguagem" (PU §43). Cai por terra, assim, todo a priori lógico, restando apenas o uso completo a decidir o sentido ou não do ato linguístico. É a

22 Hadot, 2007, p. 49. Cf. também "Acho que resumi a minha posição com relação à filosofia quando afirmei que a filosofia deveria ser escrita apenas como uma composição poética [...] com isso, confessei também ser alguém que não consegue totalmente fazer aquilo que gostaria" (Wittgenstein, 2001, p. 56); “Assim como não sei escrever versos, do mesmo modo sei escrever em prosa apenas o suficiente e nada mais. A minha prosa tem um limite bem definido, e não posso me forçar para além dele, bem como eu não poderia escrever uma poesia. $O$ meu mecanismo é assim; e é o único mecanismo que tenho à minha disposição" (Wittgenstein, 2001, p. 114).

23 “A filosofia não pode, portanto, tentar normalizar, codificar, purificar ou explicar a linguagem cotidiana, pela boa razão de que a única linguagem com sentido é precisamente a linguagem cotidiana, e que é absolutamente impossível ultrapassá-la" (Hadot, 2007, p.79, comentando PU §124). Cf. também PU $\$ 116$ e $\$ 129$.

260 | Cad. Nietzsche, Guarulhos/Porto Seguro, v.42, n.1, p. 253-274, janeiro/abril, 2021. 
teoria que Wittgenstein elabora sob o nome de jogos de linguagem [Sprachenspielen.$^{24}$

A característica da linguagem, vista no Tractatus, de remeter a algo que está para além da própria linguagem, permanece nas Investigações filosóficas e, ao mesmo tempo, se transforma. $\mathrm{O}$ jogo linguístico não é algo que se decide na pura arbitrariedade ou mediante um acordo meramente convencional. As regras do sentido do emprego da expressão nascem, se desenvolvem e se transformam de acordo com uma experiência (compartilhada ou compartilhável) com o mundo, com uma experiência, portanto, existencial. Podem existir tantos infinitos jogos linguísticos possíveis quanto são infinitas as experiências existenciais. O jogo linguístico é, portanto, a forma de expressão de um fundamento extralinguístico, ou seja - a vida. É a expressão de uma forma de viver (Lebensform) ${ }^{25}$ : "representar uma linguagem significa imaginar uma forma de vida" (PU §19). “A expressão 'jogo de linguagem' deve salientar aqui que falar uma língua é parte de uma atividade ou de uma forma de vida" (PU §23). A concepção fundamental que Hadot extrai da teoria dos jogos de linguagem e aplica à linguagem da filosofia, criando um novo instrumento exegético é, assim, o fato de que não existe uma linguagem única, mas uma multiplicidade de usos de linguagem que desenvolvem múltiplas funções, a depender da forma de vida (extralinguística) à qual remetem e, remetendo, mostram [aufweisen]. O que Wittgenstein afirma no parágrafo 304 das Investigações vale, portanto, também para os textos filosóficos: devemos "romper radicalmente com a ideia de que a linguagem funciona sempre de um único modo, presta-se

\footnotetext{
24 Daqui a ideia decisiva de Hadot: "É devido aos jogos linguísticos que tive, pela primeira vez, a ideia de que a filosofia fosse também exercício espiritual, porque, no fundo, o exercício espiritual é muito frequentemente um jogo linguístico: trata-se de dizer uma frase para provocar um efeito, seja nos outros, seja em si próprio, portanto, em certas circunstâncias e com um certo objetivo. Além disso, no mesmo contexto, Wittgenstein também usava a expressão 'forma de vida'. Também isso me inspirou a compreender a filosofia como forma de vida ou modo de vida" (Hadot, 2008, p. 181).

25 "A minha concepção da filosofia antiga é um modo de vida, uma forma de vida, uma escolha de vida" (Hadot, 2008, p. 127).
}

Cad. Nietzsche, Guarulhos/Porto Seguro, v.42, n.1, p. 253-274, janeiro/abril, 2021.| 261 
Busellato, S.

sempre ao mesmo objetivo: transmitir pensamentos". ${ }^{26}$ Também "o filósofo sempre está em um certo jogo linguístico, isto é, em uma certa atitude, em uma certa forma de vida, e é impossível dar um sentido aos textos dos filósofos sem situá-los em seu jogo linguístico". ${ }^{27}$

Estamos habituados a acreditar que a palavra filosófica seja sempre a comunicação de um pensamento, a parte de um sistema, a exposição de um conteúdo doutrinal do qual o autor quer nos tornar partícipes e que nós devemos compreender dentro das coordenadas da objetividade. Mas, diz Hadot, não era assim para os gregos. E não era assim para Nietzsche. O discurso filosófico grego, retomando uma expressão de Goldschmidt, ${ }^{28}$ não visava informar, mas formar o fruidor. ${ }^{29}$ Desenvolvia-se no âmbito da dimensão oral e de um público conhecido, não de um leitor universal (Hadot, usando uma expressão nietzschiana, afirma que, para um grego, um ensinamento para todos seria um ensinamento para nenhum ${ }^{30}$ ). Não se desenvolvia em direção da busca da certeza, mas de uma persuasão íntima da pessoa na sua totalidade. Não queria ser uma construção teórica em primeira instância, mas queria atingir uma transformação práticoexistencial, "formar uma nova maneira de viver e de ver o mundo [...] um esforço para transformar o homem". ${ }^{31}$ Todas elas características que, para Hadot, pertencem também à filosofia de Nietzsche. E, em

26 Cfr. Hadot, 2007, p. 87 e p. 98.

27 Hadot, 2007, p. 110. Hadot frequentemente cita a afirmação de Pierre Courcell: "um texto deve ser interpretado em função do gênero literário ao qual pertence" (cf. P. Hadot, Éloge de la philosophie antique. Paris: Éditions Allia, 1998; trad. it. a cura di Francesco Chiossone. Elogio della filosofia antica. Genova: Il Melangolo, 2012a, p.16-20).

28 Victor Goldschmidt. Les Dialogues de Platon: structure et méthode dialectique. Paris: Presses Universitaires de France, 1947, p. 3. Veja-se Hadot, 2008, p.76,88, 124.

29 "Sobretudo a obra, também se claramente teórica e sistemática, é escrita não tanto para informar ao leitor sobre o tema do conteúdo doutrinal, quanto para formá-lo, fazendo-o percorrer um determinado itinerário no curso do qual ele progredirá espiritualmente" (Hadot, 2012a, p. 46). Cf. também Hadot, 2008, p. 121-124.

30 Hadot, 2012, p. 78.

31 P. Hadot, Exercices spirituels et philosophie antique. Paris: Albin Michel, 2002; trad. it. di Anna Maria Marietti. Esercizi spirituali e filosofica antica. Torino: Einaudi, 2005, p. 66.

262 | Cad. Nietzsche, Guarulhos/Porto Seguro, v.42, n.1, p. 253-274, janeiro/abril, 2021. 
Nietzsche, no §2 de Schopenhauer como educador, Hadot identifica uma citação não explícita de Hölderlin que ele toma como moto válido para todas aquelas filosofias que se apresentam como Lebensform filosófica antes mesmo do que como doutrina pura: "Quem pensou as coisas profundas, ama as coisas mais vivas [Wer das Tiefste gedacht, libt das Lebendigste]" ${ }^{32}$

4. Indagar filosofias desse tipo sem perceber as diferenças que as separam das filosofias de natureza teórica, sistemática, informativa, especulativa ou, em uma palavra - diz Hadot, acadêmica ${ }^{33}$ - significa ler alguns textos - que, em vez disso, não pertencem a essa natureza expressiva - com aquilo que podemos chamar de uma verdadeira dislexia: lemos coisas que não estão escritas; não as lemos como estão escritas; não conseguimos ler aquilo que está escrito. ${ }^{34}$ Hadot identifica um elemento específico que revela as ocasiões nas quais cometemos um erro disléxico, uma constante, para o helenista, quando não distingue a essência e a distância que separa o discurso filosófico antigo daquele moderno e contemporâneo ao qual, em vez disso, estamos acostumados: um problema exegético

32 Hadot, 2005, p. 113. A criptocitação de Hölderlin é do poema Sokrates und Alkibiade. Hadot cita e discute o trecho da III Consideração extemporânea, OFN III/1, pp. 371-372.

33 "Uma das características da universidade é a de ser formada por professores que formam professores, de profissionais que formam profissionais. Portanto, o ensinamento não se volta mais aos homens que se pretende formar porque são homens, mas a especialistas, para que aprendam a preparar outros especialistas. É o perigo da 'escolástica' que começou a se delinear no fim da antiguidade, que se desenvolve no período medieval e do qual ainda se pode reconhecer a presença na filosofia atual. A universidade escolástica dominada pela teologia continuará a funcionar até o fim do século XVIII, mas do XVI ao XVIII, a atividade filosófica verdadeiramente criadora se desenvolverá do lado de fora da universidade, com Descartes, Espinosa, Malebranche, Leibniz. A filosofia conquistará sua autonomia com relação à teologia, mas o movimento que nasceu por razões contrárias à escolástica medieval se situará em seu próprio terreno. Ao discurso filosófico teórico, irá se contrapor um outro discurso teórico. A partir do fim do século XVIII, a nova filosofia faz seu ingresso na universidade com Wolf, Kant, Fichte, Schelling e Hegel, e daqui a para frente a filosofia, a não ser por algumas exceções como Schopenhauer e Nietzsche, está indissoluvelmente ligada à universidade, como mostram os exemplos de Bergson, Husserl ou Heidegger" (Hadot, 2005, p. 162).

34 "As múltiplas coações que se exercitam sobre o autor antigo [...] fazem com que o leitor moderno seja frequentemente desviado daquilo que ele disse e de como o disse" (Hadot, 2005, p. 21).

Cad. Nietzsche, Guarulhos/Porto Seguro, v.42, n.1, p. 253-274, janeiro/abril, 2021.| 263 
Busellato, S.

aparentemente insolúvel, que também o estudioso de Nietzsche conhece muito bem, qual seja, a contradição, a aparente incoerência, as numerosas partes que parecem contrastar de maneira insuperável com outras passagens do mesmo autor. Foi exatamente essa dificuldade que conduziu Hadot a elaborar uma visão da filosofia antiga como manière de vivre ${ }^{35}$, a aplicar, portanto, àqueles textos, a teoria da linguagem wittgensteiniana, a qual, no Tractatus, lhe havia revelado a função indicativa da linguagem, que aponta na direção daquilo que a linguagem não é, e, nas Investigações filosóficas, aquela do jogo linguístico, que mostra a forma de vida correspondente em uma relação na qual o bios sempre precede e decide o logos.

Isso "explica as incoerências e as contradições que os historiadores modernos descobrem com estupefação nas obras dos filósofos antigos". ${ }^{36}$ Procuramos harmonizar as partes de um discurso filosófico antigo em um sistema porque acreditamos que todo discurso filosófico queira ser sistema. ${ }^{37}$ Mas encontramos contradições, porque aqueles discursos não possuem o teórico como objetivo principal, mas "estão a serviço da vida filosófica" ${ }^{38}$ Querem, portanto, operar uma transformação do bios através do logos: possuem uma função psicagógica, qual seja, a de conduzir a psiché a um lugar de transformação de si. E, com respeito a esse lugar, importa onde alcançá-lo, não como alcançá-lo. ${ }^{39}$ Para chegar até ali, o autor pode propor diferentes estradas, até mesmo estradas divergentes. Não se preocupa que estejam coligadas ou ordenadas de acordo com um

35 Hadot, 2008, p. 82.

36 Hadot, 2008, p. 63.

37 “Que existam contradições nas filosofias antigas deve-se ao fato de que "não são sistemas"' (Hadot, 2008, p. 202).

38 Hadot, 2008, p. 158.

39 Escreve Hadot: "é [...] a necessidade da psicagogia, do guia da alma, que impede o discurso filosófico antigo de ser perfeitamente sistemático" (P. Hadot, La felicità degli antichi. Milano: Cortina Editore, 2011, p. 63). Não é por acaso que Hadot sublinhe mais vezes o débito que o nascimento da própria concepção teve com o texto de Paul Rabbow, Seelenfiuhrung. Metodik der Exerzitien in der Antike. Munich: Kösel, 1954.

264 | Cad. Nietzsche, Guarulhos/Porto Seguro, v.42, n.1, p. 253-274, janeiro/abril, 2021. 
plano que a modernidade chama "coerência" porque o sistema assim o pede.$^{40} \mathrm{O}$ importante é chegar ao lugar de transformação de si. ${ }^{41}$ "Em um certo sentido, todos os meios são bons", escreve Hadot, ou, como diz Nietzsche: "O caminho mais curto não é o mais reto possível, mas aquele em que os ventos mais favoráveis inflam nossas velas: eis o que diz o ensinamento dos navegantes" (WS/AS 59). ${ }^{42}$

Se uma determinada forma de vida filosófica está voltada para a transformação da pessoa e isso exige um espaço muito mais amplo do que aquele que a construção de um edifício teórico pode oferecer ${ }^{43}$ a contradição assim o é apenas no interior dele, mas, em seu exterior, cessa de ser um elemento problemático que deve se encaixar em alguma coerência especulativa. Isso se mostra como uma indicação preciosa também para os leitores de Nietzsche, especialmente porque, para Hadot, Nietzsche já tinha esse ponto muito claro, e uma das passagens que ele cita de bom grado para ilustrar essa questão da contradição e da natureza diversa da reflexão antiga em comparação com aquela à qual estamos habituados (porque pensamos que a linguagem filosófica possui apenas uma única função), é um fragmento póstumo de Nietzsche, no qual, falando precisamente das filosofias helenistas e de seu valor psicagógico, escreve: "O resultado de todas as escolas e de todas as suas experiências pertencem a nós,

40 A questão da assistematicidade do pensamento de Nietzsche como pretensa razão para não considerálo plenamente um filósofo é um fenômeno muito frequente. Observado o contexto aqui exposto, mostram-se significativas as palavras de Simmel que, respondendo a Tönnies, que acusava ser, aquela de Nietzsche, uma "paradoxofia" [Paradoxsophie], rebatia que se tratava de um erro "do ponto de vista do método, criticar a valoração de alguém tendo como base um critério definitivo que este não aceita" (G. Simmel, Rezension von Ferdinand Tönnies, Der Nietzsche-Kultus. In: Deutsche Literaturzeitung, XVIII,42, 23 outubro 1897, p. 1645; Berlin, Akademie-Verlag, 1990, p. 99-104).

41 Hadot, 2011, p. 66.

42 Sobre o caminho percorrido por Hadot na elaboração da concepção da filosofia como modo de vida e uma ligação explícita desta com Nietzsche, veja-se P. Hadot, L'enseignement des antiques, l'enseignement des modernes. Paris: Éditiones Rue d'Ulm, 2010, a cura di Arnold I. Davidson, Frédéric Worms; trad. di Laura Cremonesi, Gli insegnamenti degli antichi, l'insegnamento dei moderni. Pisa: Ets, 2012, p. 38-39. Veja-se também Hadot, La filosofia antica: un'etica o una pratica, in Hadot, 2011, p. 59-82.

43 Sobre a diferença entre teórico e teorético, o primeiro em oposição à práxis, o segundo parte dela, cfr. Aristóteles, Política, VII,3,8, 1325b; Hadot, 2011, p. 75.

Cad. Nietzsche, Guarulhos/Porto Seguro, v.42, n.1, p. 253-274, janeiro/abril, 2021. | 265 
Busellato, S.

não aceitamos menos voluntariamente um artifício estoico pelo fato de termos nos apropriado das regras epicuristas". ${ }^{44}$

5. Esse objetivo das filosofias como "modos de viver", isto é, uma transformação filosófica que, através da especulação, alcance muito além dela, um filosofar não mais com um fim em si mesmo, mas "instrumento de superação de si próprio", ${ }^{45}$ que saiba provocar uma metabolé, uma transformação do olhar, de paradigmas e horizonte, um Umschlag cognitivo que o autor persegue com o intuito de conduzir o fruidor ao que Espinosa chamava um "novum institutum", um novo "modo de vida"46 - para Hadot, define o que ele diz ser um exercício espiritual. Insistindo sobre o fato de que, com essa expressão, não se tem a intenção de remeter a nada de cristão (quando muito, é o cristianismo que se conforma ao exercício espiritual pagão para se fazer aceitar como filosofia antes mesmo do que como religião), ${ }^{47}$ ele quer sublinhar o duro trabalho que o perseguir uma metamorfose filosófica da própria existência exige. Ela não é um dom, mas uma conquista que pode ser obtida apenas mediante estudo, meditação, reflexão, repetição (uma vez que os progressos se perdem facilmente aqui), e tempo - muito tempo - que é necessário dedicar a ela. $\mathrm{O}$

44 NF-1881,15[59], citado erroneamente segundo a velha numeração como NF-1881,15[57], Hadot, 2010, p. 91. Veja-se também Hadot, 2008, p.138,205, 265.

45 Hadot, 2008, p. 83.

46 B. Espinosa, Breve Tratado de Deus, do homem e do seu bem-estar, Trad. Emanuel Ângelo Fragoso e Luís Cesar Guimarães Oliva. Belo Horizonte: Autêntica Editora, 2014.

47 "Nos primeiros séculos, o cristianismo se apresentou como uma filosofia na medida em que assimilava a prática tradicional dos exercícios espirituais: Clemente de Alexandria, Orígenes, Agostinho, monasticismo. Com a escolástica medieval, a teologia e a filosofia se separam, a segunda se subordina à primeira enquanto acilla theologia, e, esvaziada dos exercícios espirituais, fornece à primeira "um material conceitual, portanto, puramente teórico" (Hadot, 2005, p. 67. Veja-se também Hadot, 2005, p. 160-162). Sobre o adjetivo "espiritual", Hadot esclarece que é para "fazer compreender como esses exercícios são obras não apenas do pensamento, mas de todo o psiquismo do indivíduo" (Hadot, 2005, p. 30).

266 | Cad. Nietzsche, Guarulhos/Porto Seguro, v.42, n.1, p. 253-274, janeiro/abril, 2021. 
exercício espiritual é "uma prática voluntária, pessoal, que visa operar uma transformação do indivíduo, uma transformação de si" ${ }^{4}{ }^{8}$

Essa transformação possui ao menos três características específicas, que não podem ser aprofundadas aqui, mas que, segundo Hadot, estão presentes também na filosofia nietzschiana e a caracterizam. O que o exercício espiritual visa modificar é a relação entre mim e mundo "graças a uma transformação interior, graças a uma mudança total do modo de ver e de viver". ${ }^{49}$ A primeira condição a ser então conquistada é a da passagem de uma vida inautêntica a uma autêntica, ou seja, o buscar conquistar uma liberdade espiritual, uma liberdade interior em face às convenções e às convenções externas, ${ }^{50}$ que é o que Nietzsche concebe com a figura do espírito livre. ${ }^{51}$ Tal liberdade interior, por sua vez, exige assumir aquilo que Hadot chama uma "visão do alto"52 que leve a perceber o mundo, segundo as palavras de Nietzsche citadas por Hadot para explicá-lo, como "totalmente redimido e afirmado", "para além de mim e de você, sentir em modo cósmico". ${ }^{33}$ Trata-se daquele "re-enlaçamento com o mundo", do qual fala Löwith, e que, para Hadot, é a essência do amor fati nietzschiano. Daqui, então, nasce, como consequência necessária, também a terceira característica, ou seja, a transformação da concepção que temos do tempo ${ }^{54}$, não mais vivido na prisão opressiva do passado, nem incumbido à temerosa esperança do

48 Hadot, 2005, p. 61. Veja-se também, P. Hadot, Plotino o lo sguardo della semplicità. Trad. Monica Guerra. Torino: Einaudi, 1999, p. 72.

49 Hadot, 2005, p. 184.

50 P. Hadot, La cittadella interiore. Trad. A. Bori e M. Natali. Milano: IBS, 2006a, p. 162.

51 "Para retomar a expressão de Nietzsche [...] uma subversão total dos valores recebidos e convencionais" (Hadot, 2008, p. 219).

52 Hadot cita também a expressão "tudo que é necessário, visto do alto" do Epílogo de $O$ caso Wagner (Hadot, 2008, p. 268 n. 27).

53 P. Hadot, Ricordati di vivere. Trad. A. C. Peduzzi. Milano: Raffaello Cortina, 2009b, p. 157 e p. 163. Também Hadot, 2006b, p. 295.

54 Hadot, 2009b, p. 22-25.

Cad. Nietzsche, Guarulhos/Porto Seguro, v.42, n.1, p. 253-274, janeiro/abril, 2021. | 267 
Busellato, S.

futuro, mas concentrado unicamente na plenitude existencial do agora, o "letus in preasens" horaciano, ${ }^{55}$ o momento culminante do presente, ou seja, o instante ao qual goethianamente dizer "Verweile doch! Du bist so schöne", que, para Hadot, é o sentido do Eterno retorno de Nietzsche.

Liberdade interior, visão do alto, valor supremo do instante. São as propriedades do exercício espiritual que provocam inevitavelmente também uma ruptura em face à vida ordinária, um distanciamento do cotidiano, ou seja - abrem, ao filósofo, as portas da solidão frente a tantos que permanecem em uma condição pré-filosófica. "Nietzsche é o indivíduo que sozinho elevou o nível geral de nossos pensamentos sobre a vida, e conseguiu isso com um forte distanciamento dos homens e das coisas que o circundavam", escreveu Colli56. Mas estando o serviço espiritual a serviço de um modo de viver -, esse distanciamento assim o é, apenas na medida em que serve para voltar ao viver de modo mais pleno e amplo. "É uma forma de conversão à vida cotidiana, na repetição dos dias e das noites", mas é uma verdadeira conversão desde que, simultaneamente, seja também "um retorno ao cotidiano após esse desenraizamento, [...] um cotidiano transformado, um lugar no qual nunca estivemos". ${ }^{57} \mathrm{O}$ dionisíaco nietzschiano é, para Hadot, um exercício espiritual dessa natureza, que pede uma valoração do existente contrária ao usual, e que exija também o retorno à existência cotidiana na maneira mais completa, ou seja, afirmativa,${ }^{58}$ tão afirmativa a ponto de excluir qualquer tipo de "memento mori", dando voz, em vez disso, à única grande exortação

55 Horácio, Odes, II,16, v. 25.

56 G. Colli. Dopo Nietzsche. Milano: Adelphi, 1974, p. 201

57 Sandra Lugier, Linguaggio ordinario ed esercizio spirituale, in Hadot, 2008, p. 81. "É precisamente nessa existência cotidiana que [o filósofo] deverá buscar tender em direção àquele modo de viver, que é completamente estranho à vida cotidiana" (Hadot, 2012, p. 34). Veja-se também Hadot, 2008, p. 133-136 e p. 270).

58 Hadot, 2009b, p. 157-158. Veja-se também Hadot, 2008, p. 215-238.

268 | Cad. Nietzsche, Guarulhos/Porto Seguro, v.42, n.1, p. 253-274, janeiro/abril, 2021. 
que Hadot ouve em Nietzsche: aquela do "memento vivere". 59 "Mas o que conta é a eterna vivacidade: que importa a "vida eterna"!" (MAI/HHI 408, "Descida ao Hades").

6. São essas as razões que levam Hadot a dizer que "é apenas com Nietzsche [...] que a filosofia volta a ser mais uma vez conscientemente uma maneira de viver e de ver o mundo, uma atitude concreta". ${ }^{60}$ Nietzsche traz, em vida, algo que havia sido perdido durante o caminho, quando a filosofia começou a se desviar cada vez mais de ser exercício espiritual. Pouco a pouco, ela perdeu o contato e a aderência com a vida, fez-se atividade de construção conceitual que visa a abstração, a argumentação, a demonstração e, cada vez mais, atividade de comentário, perdendo ou rejeitando a relação entre a elaboração filosófica e o modo de viver do filósofo. Em uma palavra, diz Hadot, de exercício espiritual e modo de vida, passou a ser "a filosofia dos professores".

Também sobre isso Hadot cita Nietzsche, uma passagem da terceira Extemporânea, na qual lemos: "a única crítica a uma filosofia que é possível e que demonstra algo, ou seja, procurar viver de acordo com ela, nunca foi ensinada nas universidades: mas sempre a crítica das palavras pelas palavras". ${ }^{61}$ A universidade, prossegue Hadot ainda citando o Nietzsche de Schopenhauer como educador, é uma instituição humana, e as instituições humanas "fazem [...] com que a vida, em uma distração contínua dos pensamentos, não venha a ser sentida". ${ }^{62}$

O convite que Hadot, portanto, extrai das filosofias como modo de viver, ou, o convite que, segundo a sua leitura, provém da filosofia nietzschiana, seria, então, aquele de abandonar a carreira acadêmica,

59 Hadot, 2009b, p. 145.

60 Hadot, 2005, p. 67.

61 Hadot, 2012b, p. 26. (SE/Co, Ext., III/1, p. 447).

62 Hadot, 2011, p. 100. Cfr. também Hadot, 2008, p. 168. 
Busellato, S.

uma vez que seria possível filosofar autenticamente apenas fora da Universidade? Talvez. Ou talvez não. Pois o apelo de Hadot, e é o mesmo que ele lê em Nietzsche, não diz respeito ao onde, mas ao como se faz filosofia. Não é por acaso que, entre os exercícios espirituais de uma filosofia que se apresenta como modo de vida, ele também indique uma das atividades que, para nós, está entre as mais habituais: aquela de ler. E é uma coincidência ainda menor que Hadot use, desta vez como citação oculta, o mesmo verbo que Nietzsche - para ele, o primeiro pensador novamente clássico em época moderna - usou para dar indicações, no prefácio da Genealogia da moral, sobre como devem ser lidos os próprios escritos: "É certo que, para praticar desse modo a leitura como arte, faz-se preciso algo que precisamente em nossos dias está bem esquecido - e que exigirá tempo, até que minhas obras sejam "legíveis" - para o qual é imprescindível ser quase uma vaca, e não um 'homem moderno': o ruminar [das Wiederkäuern]" (GM/GM, Prefácio, 8).

Escreve Hadot: “Passamos a nossa vida a 'ler', mas não sabemos mais ler, isto é, determo-nos, libertarmo-nos das nossas preocupações, retornar a nós mesmos, deixar de lado as nossas buscas por sutileza e originalidade, meditar com calma, ruminar [ruminer], deixar que os textos nos falem. É um exercício espiritual este, e um dos mais difíceis". ${ }^{63}$ Para aprender a ler uma filosofia cuja essência é algo que ultrapassa os perímetros acadêmicos, e para fazer exercícios espirituais-filosóficos com ela, está mais uma vez Wittgenstein, no caminho traçado por Hadot, a dar indicações preciosas, quando sublinha que a função cognitiva não se esgota na linguagem e que a atividade filosófica continua a prosseguir para além do discurso filosófico, o qual não tem condições de exprimir essa atividade, uma vez que escapa completamente daquilo que é linguisticamente explícito. ${ }^{64}$ Seguindo esse caminho exegético que

63 Hadot, 2005, p. 68.

64 Cfr. Hadot, 2008, p. 6-7.

270 | Cad. Nietzsche, Guarulhos/Porto Seguro, v.42, n.1, p. 253-274, janeiro/abril, 2021. 
parte de Wittgenstein e atinge o interior do pensamento nietzschiano, torna-se possível, então, perceber uma nova coloratura em uma das experiências majoritariamente conhecidas a todos os leitores de Nietzsche: aquela por meio da qual percebemos que o sentido das suas palavras e das suas páginas ultrapassa a fronteira das suas palavras, vai além de suas páginas, oferecendo ao leitor a possibilidade de transformar a própria visão existencial que, por sua vez, ultrapassa a fronteira do que dela poderia ser indicado e contemplado em nosso ensaio, ou artigo, ou conferência - e que, portanto, está destinado a permanecer no silêncio da intimidade da experiência pessoal. Sabendo, porém, dessa natureza excedente em face ao escrito e à palavra, o nosso ensaio, artigo ou conferência pode, apesar disso, apontar para aquele silêncio que o Tractatus mostrou ser significativo e decisivo, e que as Investigações filosóficas ensinaram remeter ao fundamento extralinguístico que é a vida em suas múltiplas formas. Então, talvez, tanto para as obras de Nietzsche quanto para aquilo que escrevemos sobre ele, poderão valer as palavras que Wittgenstein escreveu na célebre carta a Ficker, em 1919: “o meu trabalho consiste em duas partes: aquilo que escrevi e, além disso, tudo aquilo que não escrevi. É precisamente esta segunda parte a mais importante". 
Busellato, S.

\title{
The nietzschean interpretation of Pierre Hadot
}

\begin{abstract}
With the conception of "philosophy as a way of life", Pierre Hadot inaugurated one of the most significant changes of exegetical paradigms of the recent period. Elaborated from ancient authors, the characteristics and interpretive reasons of this new paradigm make Hadot's proposal able to encompass other times and different authors. Among these, a prominent role is entrusted to Friedrich Nietzsche, on which Hadot regularly and insistently dwells on many of his works. This article offers a reconstruction of the theoretical-philosophical path that led the French scholar to elaborate his own interpretative conception and aims to show the reading that, within it, is made of the Nietzschean philosophical specificities. Hadot's conception shows itself as a different approach to the pages of Nietzsche and presents elements of great originality with a view that invites to be reflected and deepened.
\end{abstract}

Keywords: philosophy as a way of life, history of philosophy, language.

\section{Referências}

BACHMANN, Ingeborg. Sagbares und Unsagbare. Die Philosophie Ludwig Wittgensteins [1953]. In __., Werke, IV, hrsg. Christine Koschel, Inge von Weidenbaum, Clemens Münster. München: Piper Verlag, 1978; trad. it. di Barbara Agnese. In __.., Il dicibile e l'indicibile. Milano: Adelphi, 1998.

BALAUDÉ, Jean-François. Retroazione filosofica: Pierre Hadot, gli antichi e $i$ contemporanei. In: HADOT, Pierre. La philosophie comme manière de vivre. Entretiens avec Jannie Carlier et Arnold I. Davidson. Paris: Éditions Albin Michel S.A., 2001; trad. it. a cura di Anna Chiara Peduzzi e Laura Cremonesi, La filosofia come modo di vivere. Conversazioni con Jannie Carlier e Arnold I. Davison. Torino: Einaudi, 2008.

BERTRAM, Ernst. Nietzsche, Essai de Mytologie. Traduit de l'allemand par Robert Pitrou, Préface de Pierre Hadot. Paris: Édition du Félin, 1990.

COLLI, Giorgio. Dopo Nietzsche. Milano: Adelphi, 1974. 
ESPINOSA, Baruch. Breve Tratado de Deus, do homem e do seu bem-estar, Trad. Emanuel Ângelo Fragoso e Luís Cesar Guimarães Oliva. Belo Horizonte: Autêntica Editora, 2014.

GOLDSCHMIDT, Victor. Les Dialogues de Platon: structure et méthode dialectique. Paris: Presses universitaires de France, 1947.

HADOT, Pierre. La citadelle interieure Introduction aux pensée de Marc Aurèle, Paris: Fayard, 1992.

. Plotino o lo sguardo della semplicità. Trad. Monica Guerra. Torino: Einaudi, 1999.

. Exercices spirituels et philosophie antique. Paris: Albin Michel, 2002; trad. it. di Anna Maria Marietti. Esercizi spirituali e filosofica antica. Torino: Einaudi, 2005.

. La cittadella interiore. Trad. A. Bori e M. Natali. Milano: IBS, 2006a.

. Le voile d'Isis, Essai sur la histoire de l'idée de Nature. Paris: Gallimard, 2004; trad. it. di Davide Tarizzo. Il velo di Iside. Storia dell'idea di natura. Torino: Einaudi, 2006b.

. Wittgenstein et les limites du langage. Paris: J.Vrin, 2004; trad. italiana a cura de Barbara Chitussi. Wittgenstein e i limiti del linguaggio. Torino: Bollati Boringuieri, 2007.

. La philosophie comme manière de vivre. Entretiens avec Jannie Carlier et Arnold I. Davidson. Paris: Éditions Albin Michel S.A., 2001; trad. it. a cura di Anna Chiara Peduzzi e Laura Cremonesi, La filosofia come modo di vivere. Conversazioni con Jannie Carlier e Arnold I. Davison. Torino: Einaudi, 2008.

. N'oublie pas de vivre. Goethe et la tradition des exercices spirituais, Paris: Édition Michel Albin S.A., 2008; trad. it. di Anna Chiara Peduzzi. Milano: Raffaello Cortina Editore, 2009a. $2009 \mathrm{~b}$

Ricordati di vivere. Trad. A. C. Peduzzi. Milano: Raffaello Cortina, . La felicità degli antichi. Milano: Cortina Editore, 2011. 
Busellato, S.

Éloge de la philosophie antique. Paris: Éditions Allia, 1998; trad. it. a cura di Francesco Chiossone. Elogio della filosofia antica. Genova: Il Melangolo, 2012a.

. L'enseignement des antiques, l'enseignement des modernes. Paris: Éditiones Rue d'Ulm, Paris, 2010, a cura di Arnold I. Davidson, Frédéric Worms; trad. italiana di Laura Cremonesi, Gli insegnamenti degli antichi, l'insegnamento dei moderni. Pisa: Ets, 2012b.

LUGIER, Sandra, Linguaggio ordinario ed esercizio spirituale, in HADOT, P. La filosofia come modo di vivere. Torino: Einaudi, 2008.

SIMMEL, Georg. Rezension von Ferdinand Tönnies, Der Nietzsche-Kultus. In «Deutsche Literaturzeitung», XVIII,42, 23 outubro 1897, p. 1645; Berlin, Akademie-Verlag, 1990.

WITTGENSTEIN. Tractatus Logico-Philosophicus. Trad. Luiz Henrique Lopes dos Santos. São Paulo: Editora da Universidade de São Paulo, 1994.

. Pensieri diversi. A cura di Georg Henrik von Wright con la collaborazione di Heikki Nyman. Ed. italiana a cura di Michele Ranchetti. Milano: Adelphi, 2001 .

Enviado: 07/11/2020

Aceito: 12/12/2020

274 | Cad. Nietzsche, Guarulhos/Porto Seguro, v.42, n.1, p. 253-274, janeiro/abril, 2021. 